\title{
Effect of soil condition on seismic response of isolated base buildings
}

\author{
Amer Hassan $^{1} \cdot$ Shilpa Pal ${ }^{1}$ \\ Received: 20 March 2017 / Accepted: 18 August 2018 / Published online: 3 September 2018 \\ (c) The Author(s) 2018
}

\begin{abstract}
In the present paper, nonlinear time history and response spectrum analyses were carried out using Etabs-2015 software to study the influence of soil condition beneath the isolated base. The effects of soil flexibility are considered in the current study to examine the differences in spectral acceleration, base shear, story displacements, story drifts and story shear obtained following the seismic provisions of Indian standard code. Various soils are systematically compared and discussed for a seismic performance of multistory buildings. Parametric analysis of the buildings fitted with isolation devices is carried out to choose the appropriate type of soil. The study shows that the value of base shear increases with an increase of soil flexibility and superstructure stiffness. It also observed that the spectral acceleration (SA) and spectral displacement (SD) are higher in soft soil condition, which gives us evidence that the response spectral of a structure is associated with soil condition. The paper concluded that the hard soil and medium soil are suitable for base isolation building. In addition, analysis and design considerations for base isolated and conventional structures are suggested to enable the designer to get a better understanding at the preliminary design stage.
\end{abstract}

Keywords Isolated base (IB) · Fixed base (FB) - Time history analysis · Response spectrum (RS) - Acceleration . Displacement $\cdot$ Base shear $\cdot$ Story forces

\section{Introduction}

The soil condition is an essential field of analysis in earthquake engineering; this soil condition is defined as (Dexter 1988) "The physical condition of the soil and its dynamic properties, which can be divided according to standard Indian code into; hard soil (Rocky), medium soil, soft soil (loose). In view of structural engineering (Mondal and Jain 2005), the engineering community discussed SSI only when the basement motion by interaction forces as compared to the ground motion of free field (Alam and Bhuiyan 2013). The force and deformation in the supporting soil cause vibration of structure and produce base shear, moment and displacement (Hatami 2015; Baratta et al. 2008).

Amer Hassan

ameralburay@gmail.com; asahassan@myamu.ac.in

Shilpa Pal

shilpa@gbu.ac.in

1 Civil Engineering Department, School of Engineering, Gautam Buddha University, Greater Noida, UP 201312, India
During the recent decades, extensive researches have been conducted regarding the effects of soil-structure interaction (SSI) on the seismic responses of the structures. It was found that the interaction between soil and structure results in a decrease of the fundamental frequency of the response and a modification in the energy dissipation, which is attributed to radiation and material damping in the soil. In spite of the buildings are of the same region, same configuration and same earthquake magnitude, the damages that occur during the earthquake are not of the same pattern (Jayalekshmi and Chinmayi 2016). This means that there are some factors that affect the damage pattern like ground motion characteristics, soil condition under foundations, structural system of plan, mass, stiffness, and vertical irregularities (Magade and Patankar 2008; Gjorgjiev 2012; Jain 2003).

The present paper is discussing that the dynamic response of the structure is provided by isolators in the base of the structure under three altered condition of soil, which are: hard soil (I), medium soil (II) and soft soil (III), and discuss their seismic response such as, story displacement, story drift, story force, spectral acceleration and spectral displacement. This work has been done by Etabs software using time history and response spectrum analyses. 
Fig. 1 Response spectrum function

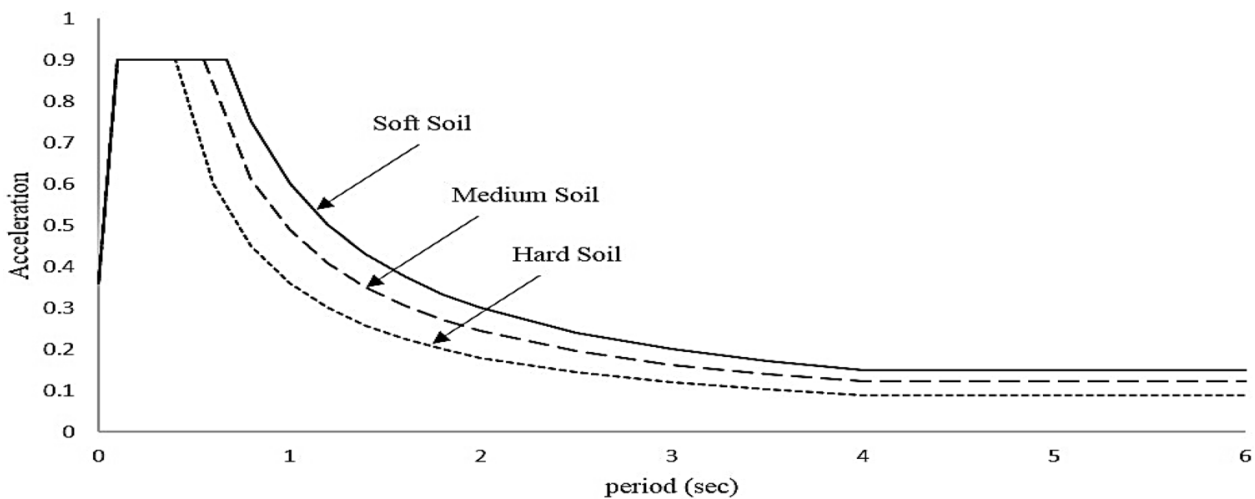

Figure 1 shows that the response spectrum function, according to IS 1893: 2002 code (Jain 2003) for various soil conditions, taking into account seismic zone $(Z)=\mathrm{IV}=0.36$ and ratio damping is 5\% (Sayani and Ryan 2009; Pietra et al. 2015).

\section{Modeling and analysis of multi-storey building}

The three-dimensional reinforced concrete structures were modeled and analyzed in response spectrum analysis (RSA) and time history analysis (THA) considering fast nonlinear analysis (FNA) using ETABS software to indicate the likely maximum seismic response of an elastic structure. The analysis results will show the performance levels and the behavior of the structures. To perform dynamic analysis in ETABS, following steps must be followed: (i) geometric modeling, (ii) sectional properties and material properties, (iii) supports: boundary conditions, (iv) loads and load combinations (dynamic) (v) analysis specification and design command (CSI 2013).

For the present work, 12 stories have been modeled and Indian code (IS) has been taken into consideration (O. F. I.
Standards 2000). Material properties, section properties, isolator characteristics (Hassan and Pal 2017), type of soil, and loads are shown in Table 1.

Response spectrum analysis and time history analysis performed on a regular building as shown in Fig. 2, by Etabs-2015 software. The El Centro earthquake matched with response spectrum using time domain method (Figs. 3, 4 and 5) (Strong-Motion Virtual Data Center (VDC) 2014; Seifried and Baker 2016; Naeim and Lew 1995), for considering the effect of soil in time history function. The story displacement, story drift, story shear forces, spectral acceleration and spectral displacement were calculated for each floor and the graph plotted for each structure.

\section{Story displacements}

Table 2 demonstrates the maximum displacement of isolated base and fixed base carried out by response spectrum analysis (RSA) for three cases, which are: hard soil, medium soil, and soft soil conditions, the results of isolated base model show that at top floor the hard soil condition produces $27.7 \mathrm{~mm}$ as fixed base produced $25.4 \mathrm{~mm}$ with $8.3 \%$ difference. It also observed that the displacement

Table 1 Input data

\begin{tabular}{llll}
\hline Grade of concrete & M 25 & Zone factor $(Z)$ & 0.36 \\
Grade of steel & Fe 415 & Response reduction factor $(R)$ & 5.0 \\
$\begin{array}{l}\text { Floor to floor height } \\
\text { Ground floor height }\end{array}$ & $3.5 \mathrm{~m}$ & Importance factor $(I)$ & 1.0 \\
& $3.5 \mathrm{~m}$ & Soil type & Hard soil-I \\
& & & Medium soil-II \\
Dead load & $1.5 \mathrm{kN} / \mathrm{m}^{2}$ & ECC. ratio $(e)$ & Soft soil-III \\
Slab thickness & $150 \mathrm{~mm}$ & Effective stiffness $\left(K_{\text {eff }}\right)$ & 0.05 \\
Wall partition on beams & $2 \mathrm{kN} / \mathrm{m}$ & Force at 0 displacement $\left(F_{0}\right)$ & $79148.6 \mathrm{kN} / \mathrm{m}$ \\
Internal wall & $150 \mathrm{~mm}$ & Stiffness of rubber in LBR $(\mathrm{Kr})$ & $1000 \mathrm{kN} / \mathrm{m}$ \\
Columns & $450 \times 450 \mathrm{~mm}$ & Bearing horizontal stiffness $(\mathrm{Kb})$ & $72932.28 \mathrm{kN} / \mathrm{m}$ \\
Beams & $300 \times 600 \mathrm{~mm}$ & Total bearing vertical stiffness $(\mathrm{kv})$ & $253869.3 \mathrm{kN} / \mathrm{m}$ \\
Live load on all floors & $3 \mathrm{kN} / \mathrm{m}^{2}$ & Damping ratio & $5 \%$ \\
\hline
\end{tabular}



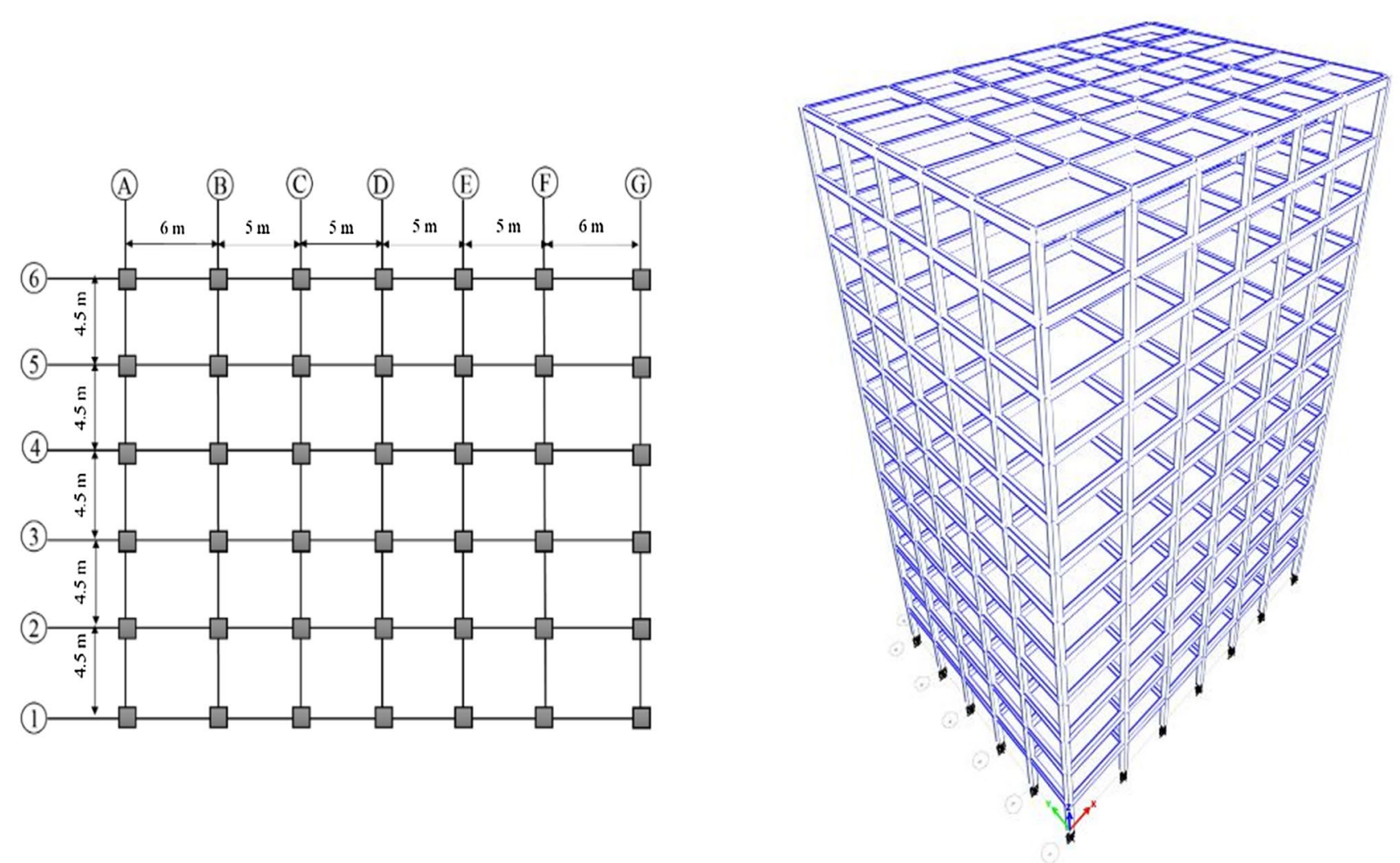

Fig. 2 Geometric of the building

Fig. 3 Matched response spectrum-time history function (El Centro 1940)—hard soil

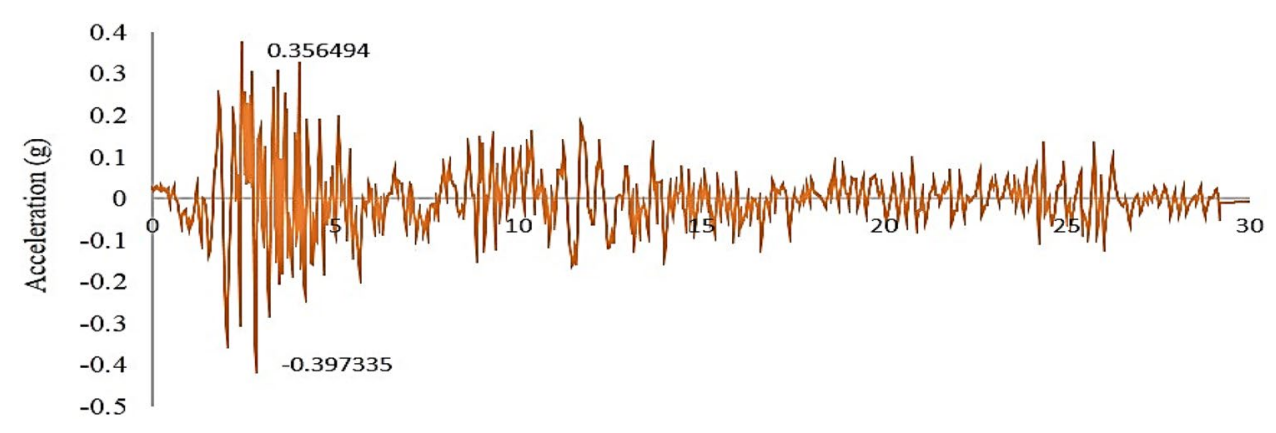

Fig. 4 Matched response spectrum-time history function (El Centro 1940)—medium soil

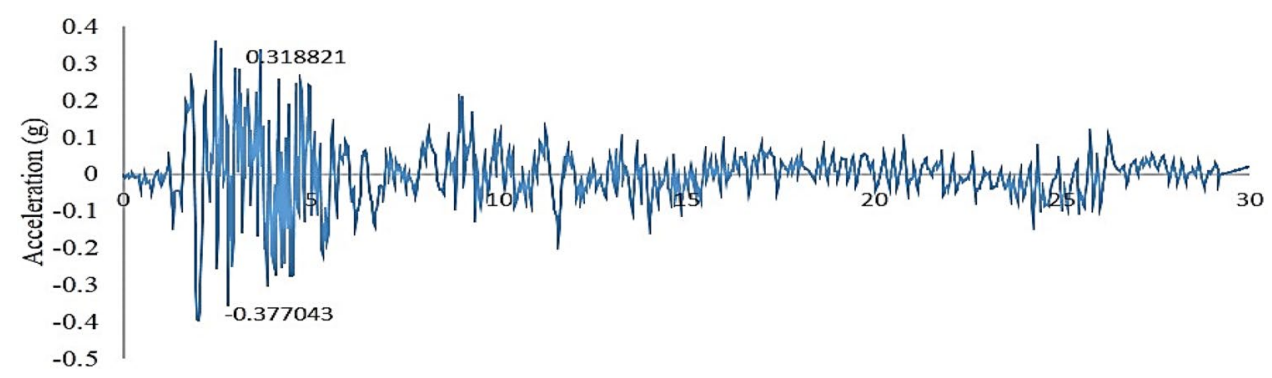

story of the isolated base model at the roof is $37.8 \mathrm{~mm}$ and $43.87 \mathrm{~mm}$ for medium soil condition and soft soil condition, respectively.
Similarly, Table 3 shows that the story displacement of the isolated base and fixed base calculated by time history analysis (THA) for various soil conditions, according to 
Fig. 5 Matched response spectrum-time history function (El Centro 1940)—soft Soil

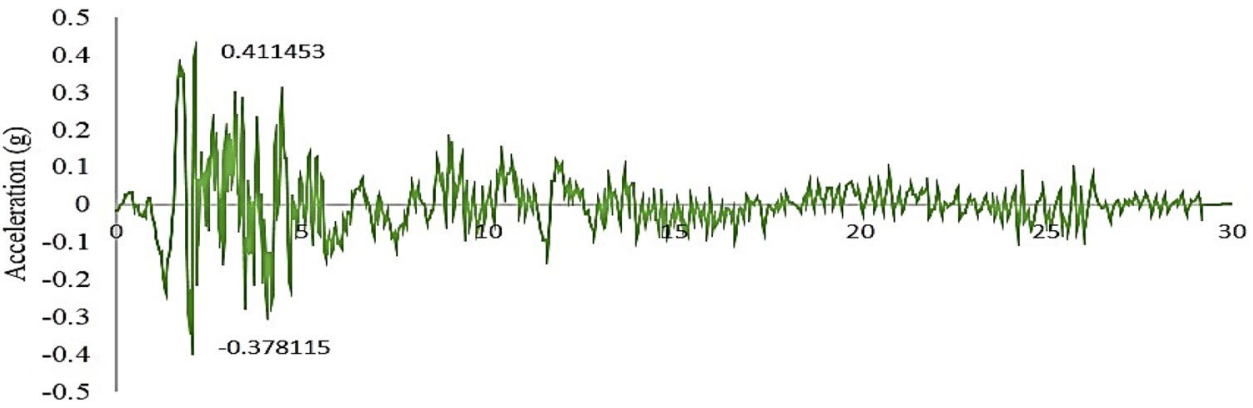

Table 2 Story displacements, response spectrum analysis, $x$-direction $(\mathrm{mm})$

\begin{tabular}{|c|c|c|c|c|c|c|c|c|c|}
\hline \multirow[t]{2}{*}{ No. of story } & \multicolumn{3}{|c|}{ Hard soil } & \multicolumn{3}{|c|}{ Medium soil } & \multicolumn{3}{|c|}{ Soft soil } \\
\hline & FB & IB & Diff\% & FB & IB & Diff\% & FB & IB & Diff\% \\
\hline 12 & 25.4 & 27.7 & 8.3 & 25.7 & 37.8 & 32.01 & 26.1 & 46.5 & 43.87 \\
\hline 11 & 24.9 & 27.3 & 8.79 & 25.2 & 37.2 & 32.26 & 25.5 & 45.8 & 44.32 \\
\hline 10 & 24 & 26.6 & 9.77 & 24.3 & 36.2 & 32.87 & 24.6 & 44.6 & 44.84 \\
\hline 9 & 22.7 & 25.6 & 11.33 & 23 & 34.8 & 33.91 & 23.3 & 42.8 & 45.56 \\
\hline 8 & 21.1 & 24.2 & 12.81 & 21.4 & 33 & 35.15 & 21.7 & 40.6 & 46.55 \\
\hline 7 & 19.2 & 22.6 & 15.04 & 19.4 & 30.8 & 37.01 & 19.7 & 37.9 & 48.02 \\
\hline 6 & 17 & 20.7 & 17.87 & 17.2 & 28.2 & 39.01 & 17.4 & 34.7 & 49.86 \\
\hline 5 & 14.5 & 18.6 & 22.04 & 14.7 & 25.4 & 42.13 & 14.9 & 31.2 & 52.24 \\
\hline 4 & 11.8 & 16.3 & 27.61 & 12 & 22.2 & 45.95 & 12.1 & 27.3 & 55.68 \\
\hline 3 & 8.9 & 13.8 & 35.51 & 9 & 18.8 & 52.13 & 9.1 & 23.1 & 60.61 \\
\hline 2 & 5.8 & 11.1 & 47.75 & 5.8 & 15.1 & 61.59 & 5.8 & 18.5 & 68.65 \\
\hline 1 & 2.5 & 7.8 & 67.95 & 2.5 & 10.6 & 76.42 & 2.5 & 13 & 80.77 \\
\hline Base & 0 & 0 & 0 & 0 & 0 & 0 & 0 & 0 & 0 \\
\hline
\end{tabular}

Table 3 Story displacements, time history analysis, $x$-direction $(\mathrm{mm})$

\begin{tabular}{|c|c|c|c|c|c|c|c|c|c|}
\hline \multirow[t]{2}{*}{ No. of story } & \multicolumn{3}{|c|}{ Hard Soil } & \multicolumn{3}{|c|}{ Medium Soil } & \multicolumn{3}{|c|}{ Soft Soil } \\
\hline & FB & IB & Diff\% & FB & IB & Diff\% & FB & IB & Diff\% \\
\hline Base & 0 & 0 & 0.00 & 0 & 0 & 0.00 & 0 & 0 & 0.00 \\
\hline 1 & 2.1 & 7.8 & 73.08 & 3.4 & 10.5 & 67.62 & 1.9 & 12.8 & 85.16 \\
\hline 2 & 5 & 10.8 & 53.70 & 8 & 14.8 & 45.95 & 4.5 & 17.9 & 74.86 \\
\hline 3 & 7.9 & 13 & 39.23 & 12.4 & 18.2 & 31.87 & 6.9 & 21.5 & 67.91 \\
\hline 4 & 10.8 & 14.7 & 26.53 & 16.7 & 21.1 & 20.85 & 9.1 & 24.4 & 62.70 \\
\hline 5 & 13.5 & 17 & 20.59 & 20.7 & 23.8 & 13.03 & 11.1 & 26.5 & 58.11 \\
\hline 6 & 16.3 & 19.2 & 15.10 & 24.1 & 26.2 & 8.02 & 13 & 28.8 & 54.86 \\
\hline 7 & 18.8 & 21.8 & 13.76 & 26.9 & 28.2 & 4.61 & 14.6 & 31.4 & 53.50 \\
\hline 8 & 21.1 & 24.1 & 12.45 & 29 & 29.9 & 3.01 & 15.9 & 33.6 & 52.68 \\
\hline 9 & 23.1 & 25.8 & 10.47 & 30.7 & 31.6 & 2.85 & 17.2 & 35.4 & 51.41 \\
\hline 10 & 24.6 & 27.3 & 9.89 & 32.2 & 32.9 & 2.13 & 18.2 & 36.7 & 50.41 \\
\hline 11 & 25.7 & 28.5 & 9.82 & 33.3 & 33.7 & 1.19 & 18.8 & 37.6 & 50.00 \\
\hline 12 & 26.3 & 29.1 & 9.62 & 33.7 & 34.2 & 1.46 & 19.2 & 38.1 & 49.61 \\
\hline
\end{tabular}

IS code. It is observed that the maximum displacements at roof are $29.1 \mathrm{~mm}, 33.7 \mathrm{~mm}$ and $38.1 \mathrm{~mm}$ for hard, medium and soft soil conditions, respectively. While the results of displacement at roof in fixed base model are $26.3 \mathrm{~mm}, 33.7 \mathrm{~mm}$ and $19.2 \mathrm{~mm}$ for hard, medium and soft soil conditions, which means that story displacement decreases whenever there is increase in stiffness of soil, it also indicates that the isolated base produced displacement more than fixed base in both methods of analysis, (RSA) and (THA). It is also observed that the results of 
the time history analysis are slightly more than the results of response spectrum analysis.

The above discussion demonstrates that the isolated base provides more flexibility to the structure. It also demonstrates the effects of story displacement according to the soil condition and flexibility of the structure (Figs. 6, 7 and 8).

Response Spectrum Analysis

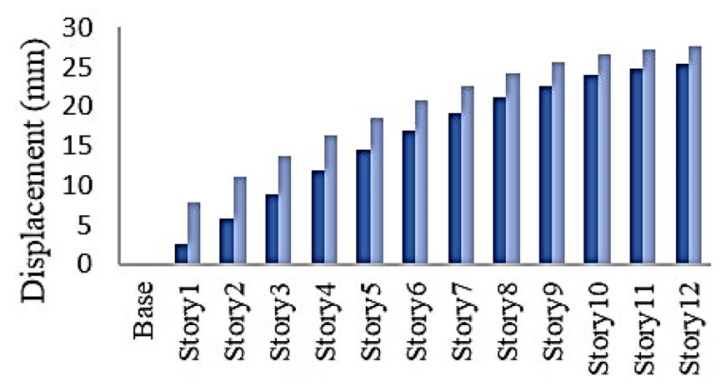

प Fixed Base $\quad$ Isloted Base

Fig. 6 Story displacements, hard soil-I

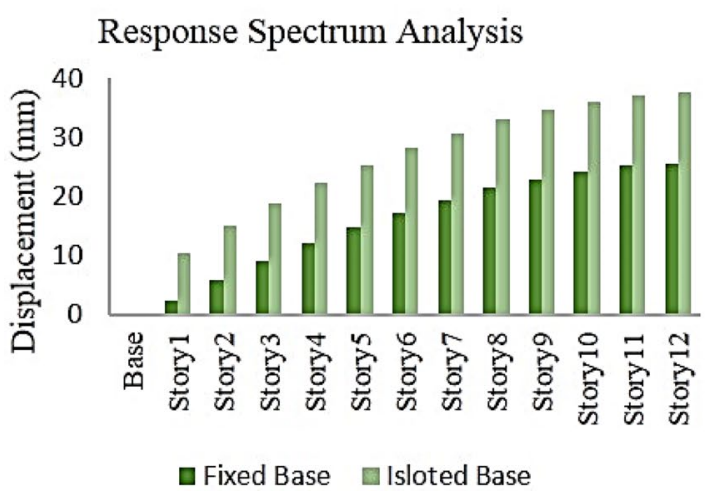

Fig. 7 Story displacements, medium soil-II

Response Spectrum Analysis

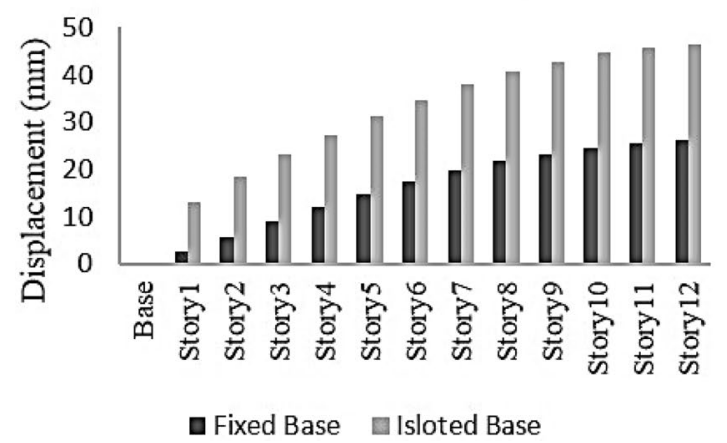

\section{Story drifts}

Story drift is defined as the variance in lateral displacement between two adjacent stories. During an earthquake, large lateral forces can be imposed on structures; lateral displacement and drift have three main effects on a structure: the movements influence on the structural components (such

Time History Analysis

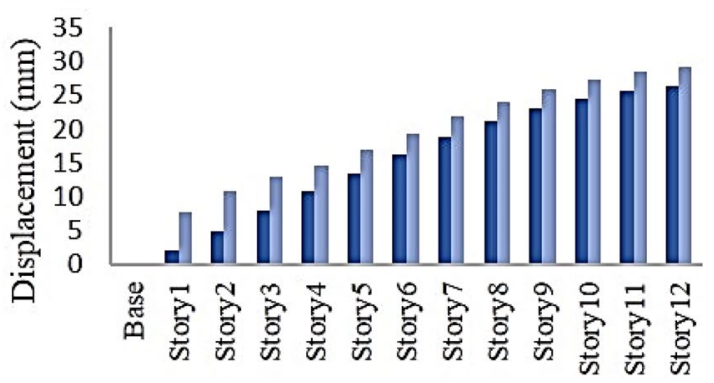

口Fixed Base Isloted Base

Time History Analysis

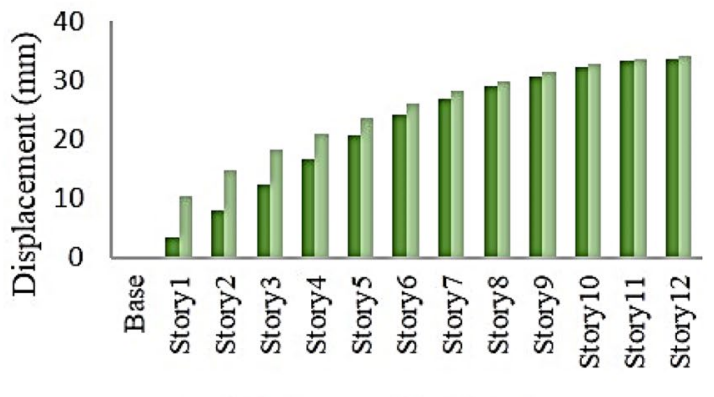

口Fixed Base Isloted Base

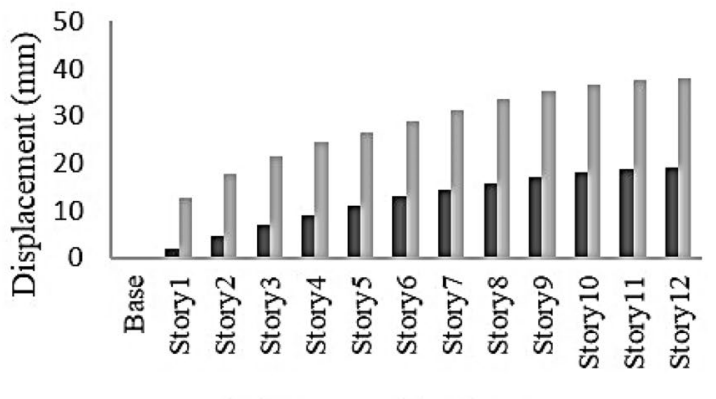

- Fixed Base Isloted Base

Fig. 8 Story displacements, soft soil-II 
as beams and columns); the movements influence on nonstructural components, and the movements influence on adjacent structures. Without appropriate consideration during the design stage, large displacements and drifts can have adverse effects on structural components, non-structural components, and adjacent structures.

Tables 4 and 5 show that the story drifts were carried out by response spectrum analysis and time history analysis. It is observed that the maximum drift seen on the first floor is produced above the isolators. It is also observed the story drift increases according to the soil's flexibility (Figs. 9, 10 and 11). Thus, the largest drifts were created in soft soil condition.

\section{Story forces}

Story shear is the sum of designed lateral forces at all levels above the story under consideration. Story shear value, as per IS code, is calculated and plotted for buildings with different heights, and resting on different soil types. Representative variations in the pattern of distribution of lateral shear force in a 12-storey building corresponding to the seismic provisions of IS code. Tables 6 and 7, it is observed that the value of story shear increases as the stiffness of the soil decreases and so forth; it is highest for the soft soil type (SS) and lowest for hard soil type (HS).

In case of hard soil, the values of story forces at first floor are $1551.43 \mathrm{kN}, 1334.38 \mathrm{kN}$ for fixed base and isolated base, respectively (see Fig. 12). It observes that the percentage reduction of story force value at first floor is $16.3 \%$ in isolated base when compared with fixed base. However, the story forces at first floor are $1552.22,1553.9 \mathrm{kN}$ for fixed base and 1814.8, 2228.5 kN for isolated base in case of medium soil condition and soft soil condition, respectively; therefore, the story forces of isolated base increases by $14.5 \%$ for medium soil and $30.3 \%$ for soft soil, as compared
Table 4 Story drifts, response spectrum analysis, $x$-direction $(\mathrm{mm})$

Table 5 Story drifts, time history analysis, $x$-direction (mm)

\begin{tabular}{|c|c|c|c|c|c|c|c|c|c|}
\hline \multirow[t]{2}{*}{ No. of story } & \multicolumn{3}{|c|}{ Hard soil } & \multicolumn{3}{|c|}{ Medium soil } & \multicolumn{3}{|c|}{ Soft soil } \\
\hline & FB & IB & Diff\% & FB & IB & Diff $\%$ & FB & IB & Diff\% \\
\hline 12 & 0.207 & 0.148 & -39.86 & 0.195 & 0.194 & -0.52 & 0.187 & 0.232 & 19.4 \\
\hline 11 & 0.364 & 0.269 & -35.32 & 0.351 & 0.355 & 1.13 & 0.339 & 0.427 & 20.61 \\
\hline 10 & 0.484 & 0.375 & -29.07 & 0.48 & 0.502 & 4.38 & 0.471 & 0.608 & 22.53 \\
\hline 9 & 0.573 & 0.46 & -24.57 & 0.579 & 0.623 & 7.06 & 0.574 & 0.76 & 24.47 \\
\hline 8 & 0.645 & 0.531 & -21.47 & 0.654 & 0.724 & 9.67 & 0.653 & 0.886 & 26.3 \\
\hline 7 & 0.709 & 0.593 & -19.56 & 0.715 & 0.808 & 11.51 & 0.717 & 0.991 & 27.65 \\
\hline 6 & 0.768 & 0.649 & -18.34 & 0.769 & 0.881 & 12.71 & 0.774 & 1.081 & 28.4 \\
\hline 5 & 0.82 & 0.7 & -17.14 & 0.821 & 0.948 & 13.4 & 0.828 & 1.162 & 28.74 \\
\hline 4 & 0.868 & 0.746 & -16.35 & 0.874 & 1.011 & 13.55 & 0.883 & 1.241 & 28.85 \\
\hline 3 & 0.914 & 0.795 & -14.97 & 0.925 & 1.081 & 14.43 & 0.935 & 1.329 & 29.65 \\
\hline 2 & 0.942 & 0.946 & 0.42 & 0.951 & 1.289 & 26.22 & 0.957 & 1.585 & 39.62 \\
\hline 1 & 0.708 & 2.219 & 68.09 & 0.71 & 3.02 & 76.49 & 0.712 & 3.709 & 80.8 \\
\hline Base & 0 & 0 & 0 & 0 & 0 & 0 & 0 & 0 & 0 \\
\hline
\end{tabular}

\begin{tabular}{|c|c|c|c|c|c|c|c|c|c|}
\hline \multirow[t]{2}{*}{ No. of story } & \multicolumn{3}{|c|}{ Hard soil } & \multicolumn{3}{|c|}{ Medium soil } & \multicolumn{3}{|c|}{ Soft soil } \\
\hline & FB & IB & Diff $\%$ & FB & IB & Diff $\%$ & FB & IB & Diff\% \\
\hline Base & 0 & 0 & 0 & 0 & 0 & 0 & 0 & 0 & 0.00 \\
\hline 1 & 0.597 & 2.216 & 73.06 & 0.982 & 2.995 & 67.21 & 0.544 & 3.655 & 85.12 \\
\hline 2 & 0.83 & 0.872 & 4.82 & 1.298 & 1.231 & -5.44 & 0.733 & 1.45 & 49.45 \\
\hline 3 & 0.844 & 0.788 & -7.11 & 1.265 & 0.988 & -28.04 & 0.703 & 1.092 & 35.62 \\
\hline 4 & 0.846 & 0.806 & -4.96 & 1.226 & 0.928 & -32.11 & 0.658 & 1.088 & 39.52 \\
\hline 5 & 0.832 & 0.864 & 3.7 & 1.143 & 0.866 & -31.99 & 0.609 & 1.059 & 42.49 \\
\hline 6 & 0.796 & 0.851 & 6.46 & 0.979 & 0.809 & -21.01 & 0.57 & 0.973 & 41.42 \\
\hline 7 & 0.736 & 0.76 & 3.16 & 0.958 & 0.737 & -29.99 & 0.523 & 0.944 & 44.6 \\
\hline 8 & 0.656 & 0.741 & 11.47 & 0.872 & 0.66 & -32.12 & 0.487 & 0.853 & 42.91 \\
\hline 9 & 0.558 & 0.663 & 15.84 & 0.724 & 0.576 & -25.69 & 0.427 & 0.715 & 40.28 \\
\hline 10 & 0.441 & 0.518 & 14.86 & 0.618 & 0.434 & -42.4 & 0.34 & 0.623 & 45.43 \\
\hline 11 & 0.327 & 0.346 & 5.49 & 0.484 & 0.326 & -48.47 & 0.235 & 0.466 & 49.57 \\
\hline 12 & 0.22 & 0.193 & -13.99 & 0.276 & 0.174 & -58.62 & 0.13 & 0.257 & 49.42 \\
\hline
\end{tabular}


Response Spectrum Analysis

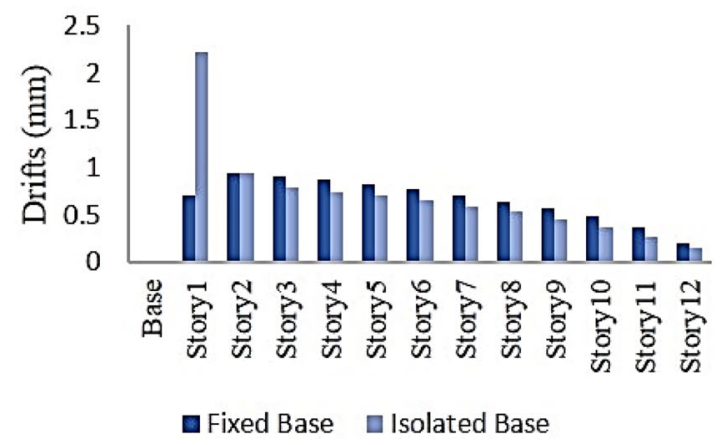

Fig. 9 Story drifts, hard soil-I

Response Spectrum Analysis

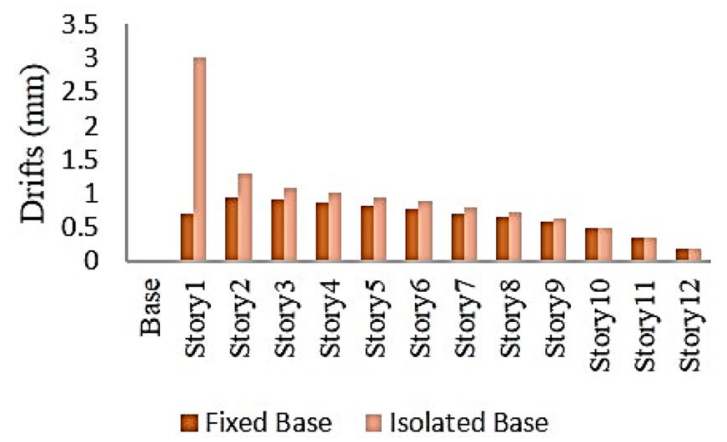

Fig. 10 Story drifts, medium soil-II

\section{Response Spectrum Analysis}

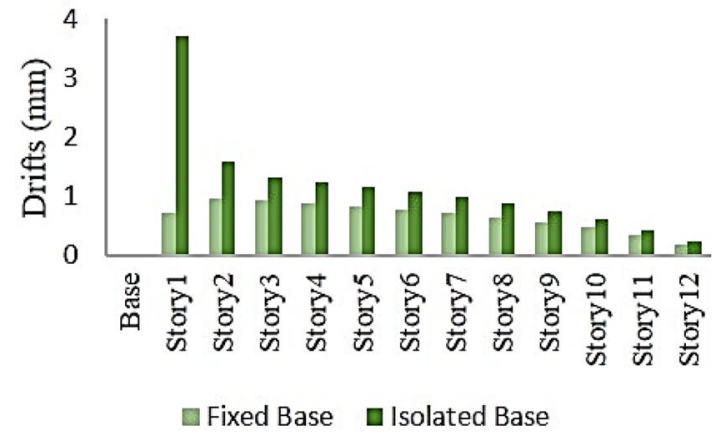

Fig. 11 Story drifts, soft soil

with a fixed base model (see Figs. 13 and 14). Subsequently, the performance of hard soil condition with isolated base model is better than that of other conditions.

It is also observed that the difference of story forces in the response spectrum analysis (RSA) as compared to the time history analysis (THA) results are negligible for same cases.
Time History Analysis

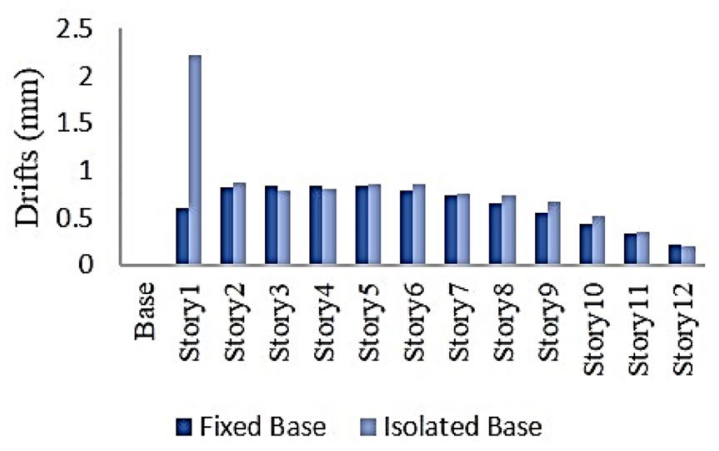

Time History Analysis

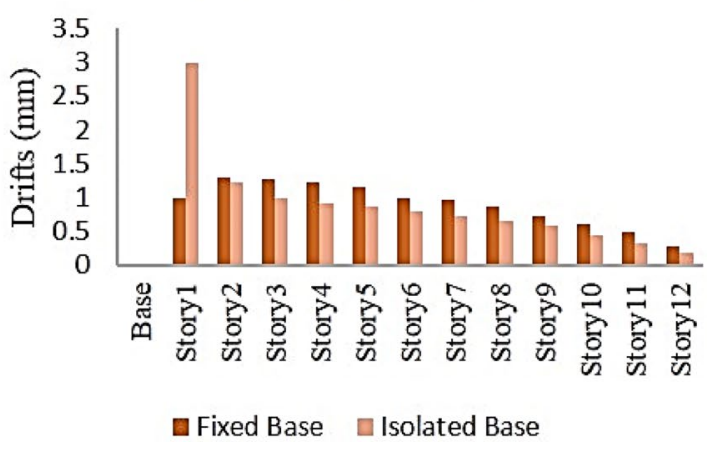

Time History Analysis

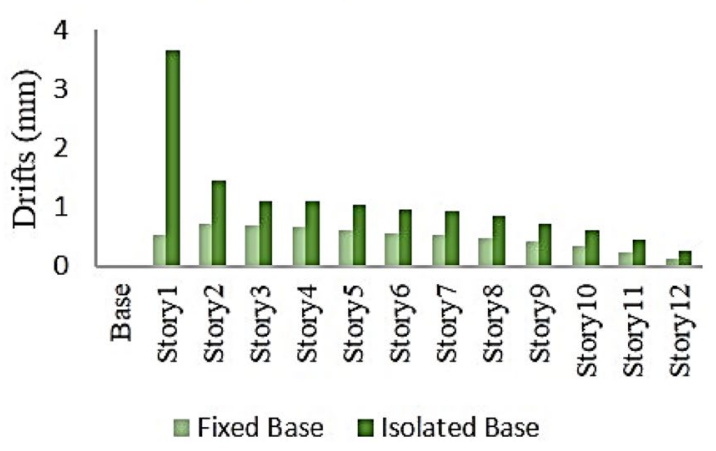

\section{Time history of base shear (Fx)}

Base shear directly depends on the input earthquake history; so if a building is not expected to be subjected to high dynamic forces, its design base shear would be low, which is good but the engineer has no control over the 
Table 6 Story forces, response spectrum analysis, $x$-direction $(\mathrm{kN})$

\begin{tabular}{|c|c|c|c|c|c|c|c|c|c|}
\hline \multirow[t]{2}{*}{ No. of story } & \multicolumn{3}{|l|}{ Hard soil } & \multicolumn{3}{|c|}{ Medium soil } & \multicolumn{3}{|l|}{ Soft soil } \\
\hline & FB & IB & Diff\% & FB & IB & Diff\% & FB & IB & Diff\% \\
\hline 12 & 276.06 & 180.97 & -52.54 & 249.77 & 230.80 & -8.22 & 233.86 & 272.50 & 14.18 \\
\hline 11 & 537.23 & 382.86 & -40.32 & 508.93 & 499.59 & -1.87 & 487.116 & 596.80 & 18.38 \\
\hline 10 & 718.94 & 545.87 & -31.71 & 708.01 & 727.78 & 2.72 & 690.48 & 879.26 & 21.47 \\
\hline 9 & 850.63 & 675.62 & -25.9 & 857.08 & 914.19 & 6.25 & 847.468 & 1113.88 & 23.92 \\
\hline 8 & 960.45 & 784.81 & -22.38 & 971.95 & 1068.46 & 9.03 & 969.376 & 1307.91 & 25.88 \\
\hline 7 & 1062.23 & 882.35 & -20.39 & 1066.93 & 1200.35 & 11.11 & 1069.16 & 1471.34 & 27.33 \\
\hline 6 & 1156.34 & 971.75 & -19 & 1152.99 & 1317.36 & 12.48 & 1158.99 & 1614.39 & 28.21 \\
\hline 5 & 1240.54 & 1053.33 & -17.77 & 1237.86 & 1424.84 & 13.12 & 1247.87 & 1746.21 & 28.54 \\
\hline 4 & 1319.6 & 1127.72 & -17.01 & 1326.35 & 1527.09 & 13.15 & 1339.64 & 1873.70 & 28.5 \\
\hline 3 & 1401.51 & 1197.79 & -17.01 & 1416.95 & 1627.52 & 12.94 & 1430.26 & 2000.13 & 28.49 \\
\hline 2 & 1486.15 & 1267.85 & -17.22 & 1499.26 & 1726.84 & 13.18 & 1507.83 & 2123.32 & 28.99 \\
\hline 1 & 1551.43 & 1334.38 & -16.27 & 1552.22 & 1814.788 & 14.47 & 1553.89 & 2228.50 & 30.27 \\
\hline
\end{tabular}

\begin{tabular}{|c|c|c|c|c|c|c|c|c|c|}
\hline \multirow[t]{2}{*}{ No. of story } & \multicolumn{3}{|c|}{ Hard soil } & \multicolumn{3}{|c|}{ Medium soil } & \multicolumn{3}{|l|}{ Soft soil } \\
\hline & FB & IB & Diff $\%$ & FB & IB & Diff $\%$ & FB & IB & Diff\% \\
\hline 12 & 250.02 & 245.21 & -1.96 & 349.71 & 228.94 & -52.75 & 242.73 & 326.82 & 25.73 \\
\hline 11 & 587.16 & 488.67 & -20.15 & 670.19 & 489.89 & -36.8 & 532.30 & 680.80 & 21.81 \\
\hline 10 & 851.33 & 751.16 & -13.33 & 941.69 & 665.12 & -41.58 & 791.53 & 930.84 & 14.97 \\
\hline 9 & 970.52 & 988.42 & 1.81 & 1193.95 & 860.25 & -38.79 & 939.05 & 1052.40 & 10.77 \\
\hline 8 & 1062.77 & 1115.74 & 4.75 & 1385.77 & 994.23 & -39.38 & 920.95 & 1267.07 & 27.32 \\
\hline 7 & 1235.80 & 1136.87 & -8.7 & 1496.40 & 1094.76 & -36.69 & 883.76 & 1418.76 & 37.71 \\
\hline 6 & 1340.98 & 1294.33 & -3.6 & 1484.56 & 1210.51 & -22.64 & 993.21 & 1459.32 & 31.94 \\
\hline 5 & 1412.81 & 1315.71 & -7.38 & 1479.49 & 1302.42 & -13.59 & 1098.50 & 1603.58 & 31.5 \\
\hline 4 & 1410.00 & 1218.63 & -15.7 & 1416.38 & 1401.71 & -1.05 & 1193.15 & 1662.52 & 28.23 \\
\hline 3 & 1481.31 & 1200.44 & -23.4 & 1504.56 & 1482.93 & -1.46 & 1343.14 & 1640.58 & 18.13 \\
\hline 2 & 1497.61 & 1158.73 & -29.25 & 1533.42 & 1643.09 & 6.67 & 1478.47 & 1932.33 & 23.49 \\
\hline 1 & 1546.81 & 1347.49 & -14.79 & 1561.92 & 1809.88 & 13.7 & 1549.52 & 2219.76 & 30.19 \\
\hline
\end{tabular}

Table 7 Story forces, time history analysis, $x$-direction $(\mathrm{kN})$

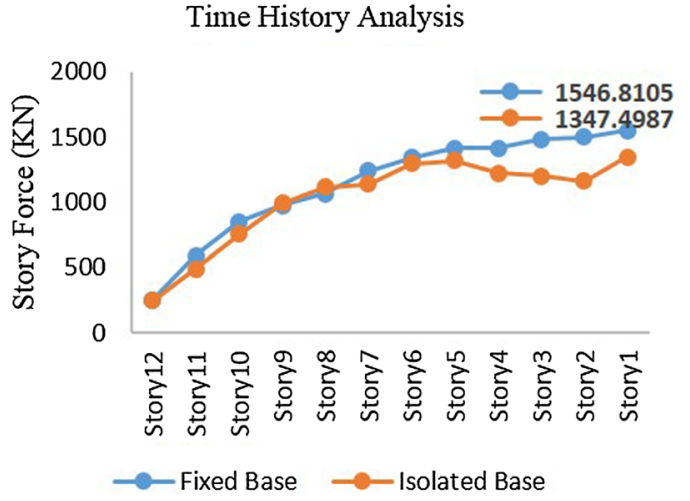

Fig. 12 Story forces, hard soil-I (kN)

design base shear. Whatever it is, one must design for it or risk structural failure. So, it does not matter whether a structure has low or high base shear. What matters is, can your structure withstand it or not? 

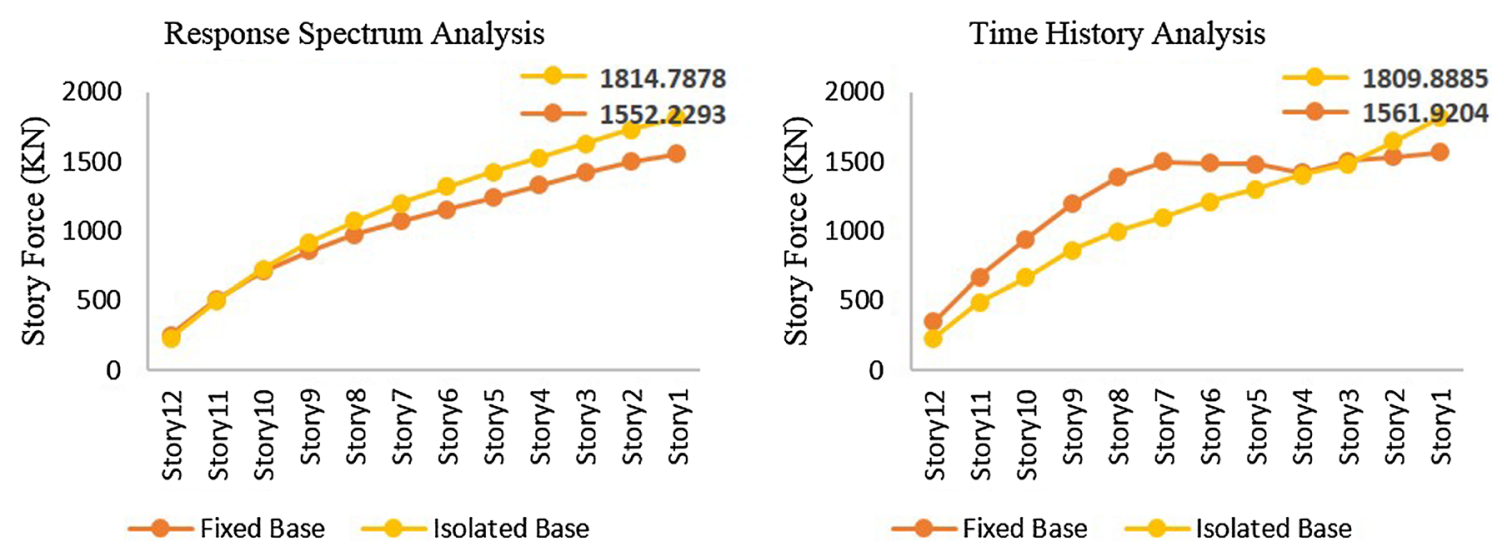

Fig. 13 Story forces, medium soil-II $(\mathrm{kN})$
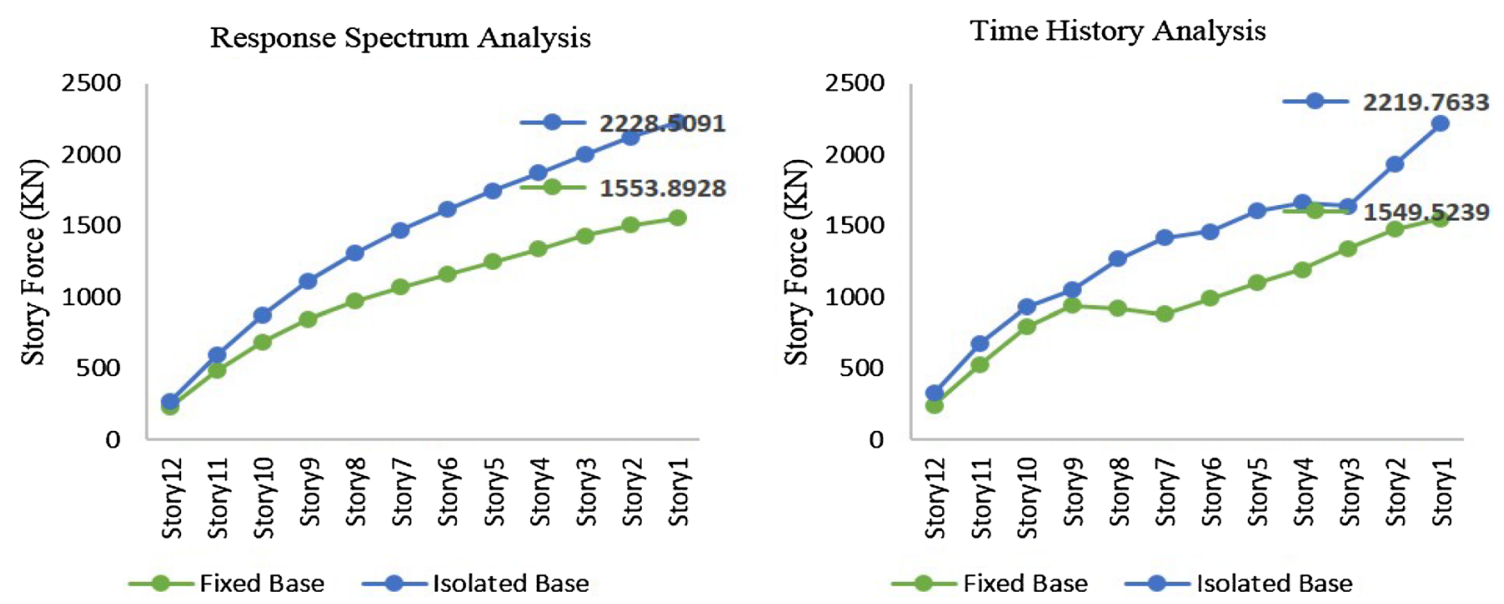

Fig. 14 Story forces, soft soil-III $(\mathrm{kN})$

In other words, base shear is an estimate of the maximum expected lateral force that will occur due to seismic ground motion at the base of a structure. Calculations of base shear $(\mathrm{V})$ depend on:

- Soil conditions at the site.

- Proximity to potential sources of seismic activity (such as geological faults).

- Probability of significant seismic ground motion.

- The level of ductility and over-strength associated with various structural configurations and the total weight of the structure.

The fundamental (natural) period of vibration of the structure when subjected to dynamic loading.

In this study, the values of base shear of the isolated base model over HS, MS, and SS soil site as per IS 1893 are as shown in Fig. 15.
It is observed that the soil condition have pronounced effects in the case of isolated base buildings. The maximum values of base shear are (1344.73), (2167.4), (2346.76) kN for hard soil, medium soil, and soft soil respectively. As shown in Fig. 15 it is found that the precentage reduction of base shear values obtained by considering the hard soil condition is $38 \%$ when compared with the medium soil condition, and $42.7 \%$ when compared with the soft soil condition. Among the soil conditions considered is found that the hard soil condition produces less base shear in the buildings.

\section{Spectral acceleration at roof}

Peak ground acceleration (PGA) is defined as the maximum ground acceleration that occurred during ground motion at a site. PGA is equal to the amplitude of the largest absolute acceleration recorded on an accelerogram at a location during a specific earthquake. Earthquakes usually occur in all three directions (Sayani and Ryan 2009). Thus, PGA is often 
Fig. 15 Time history base shear in various types of soil

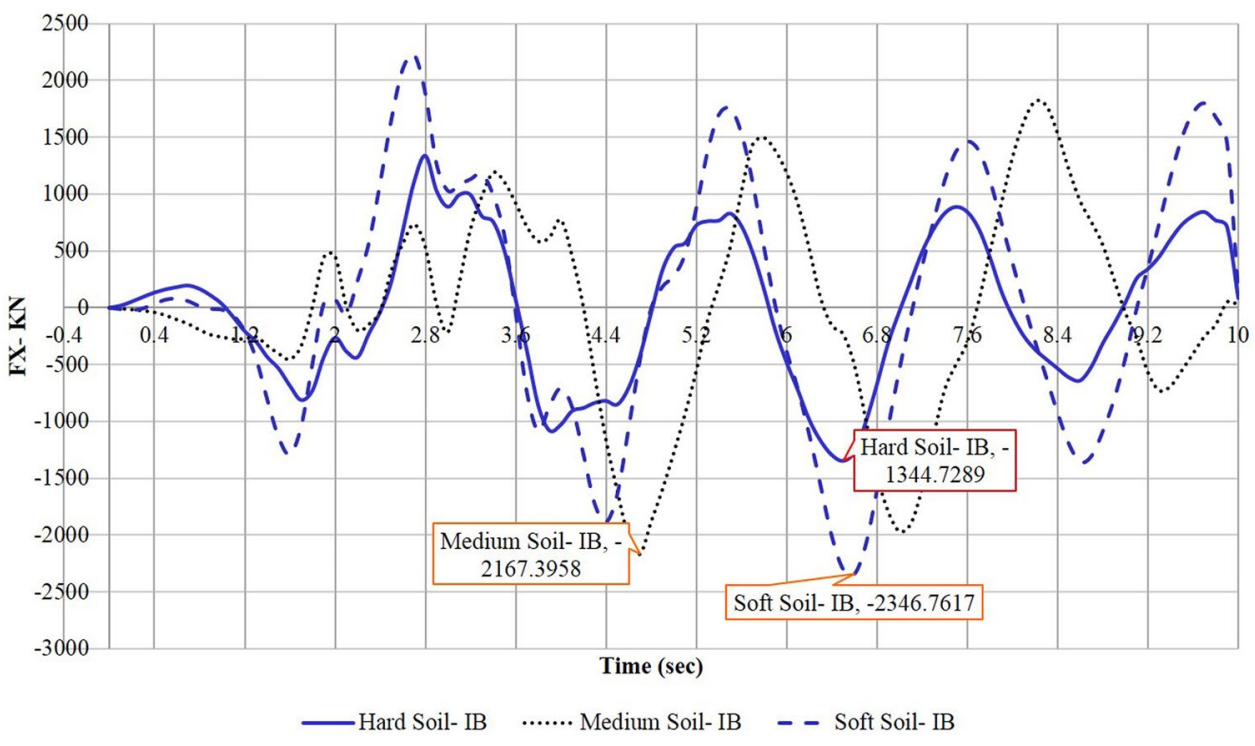

divided into the horizontal and vertical components. Horizontal PGAs are generally larger than those in the vertical direction. Therefore, the peak horizontal acceleration (PHA) is the most frequently used type of ground acceleration in engineering applications.

In the present study, the maximum values of spectral acceleration for both models are shown in (Figs. 16, 17 and 18): isolated base model and fixed base model, taking into consideration the type of soil according to IS code, shown in Fig. 19. The maximum values of spectral acceleration are; $1561.44 \mathrm{~mm} / \mathrm{s}^{2}, 1032.81 \mathrm{~mm} / \mathrm{s}^{2}$ in case of hard soil, and $2118.4 \mathrm{~mm} / \mathrm{s}^{2}, 1753.4 \mathrm{~mm} / \mathrm{s}^{2}$, in case of medium soil, for fixed base condition and isolated base condition, respectively. In the case of soft soil, the values are $1622.9 \mathrm{~mm} / \mathrm{s}^{2}$ for fixed base condition and $2015.2 \mathrm{~mm} / \mathrm{s}^{2}$ for isolated base condition. As you can see, in the case of hard soil and medium soil, the value of spectral acceleration is greater in fixed base models than in isolated base models for the same cases. Figure 19 shows that the values of spectral acceleration of isolated base model on various soil conditions. It can be observed that the soft soil condition produces higher spectral acceleration as compared with medium and hard soil conditions.

\section{Spectral displacement at roof}

The two factors affecting spectral displacement are energy dissipation by the isolators and the forces developed within the isolators themselves (Pietra et al. 2015). The spectral displacement decreases with increase in energy dissipation but increases as the isolators' forces rise. Figure 20 presents the time history of the spectral displacement at roof for the El Centro earthquake 1940 matched with the response spectrum. The peak displacements of the roof are presented in Fig. 20, illustrating that the roof produces large displacement in soft soil condition with $213.2 \mathrm{~mm}$. However, in hard soil conditions, the spectral displacement value of isolated base is $130.5 \mathrm{~mm}$ and $189.3 \mathrm{~mm}$ for medium soil condition. Thus, the increase percentage of spectral displacement in soft soil condition is $38.8 \%$ and $31 \%$ in medium soil condition when compared with hard soil condition.
Fig. 16 Spectral accelerationhard soil-I

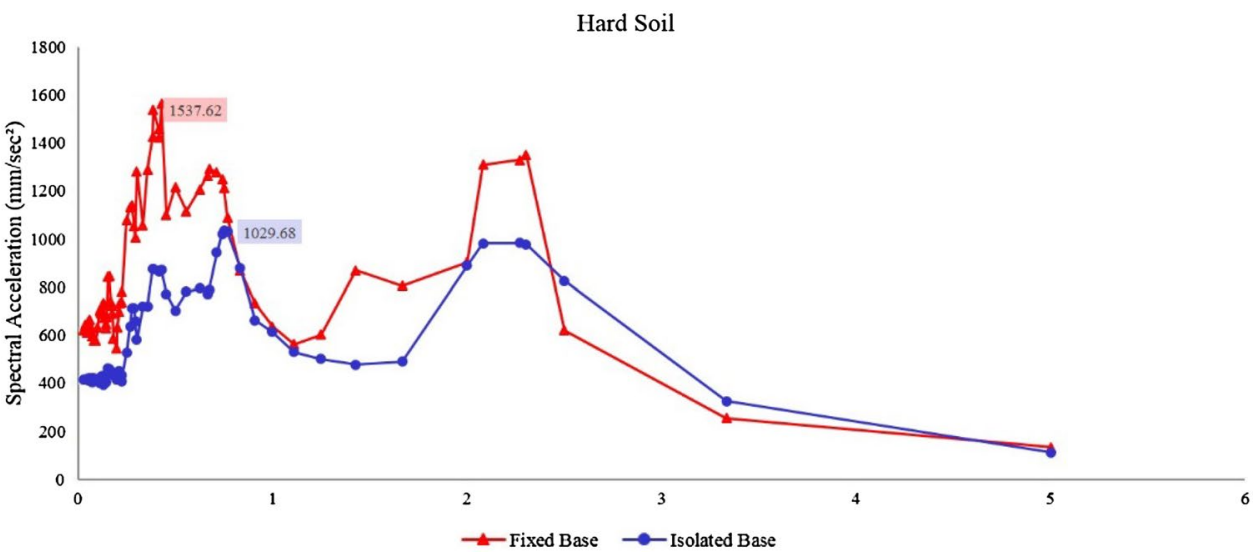


Fig. 17 Spectral accelerationmedium soil-II

Fig. 18 Spectral accelerationsoft soil-III

Fig. 19 Spectral acceleration of isolated base model in various soil conditions. IS isolated base, $H S$ hard soil, $M S$ medium soil, $S S$ soft soil
Medium Soil
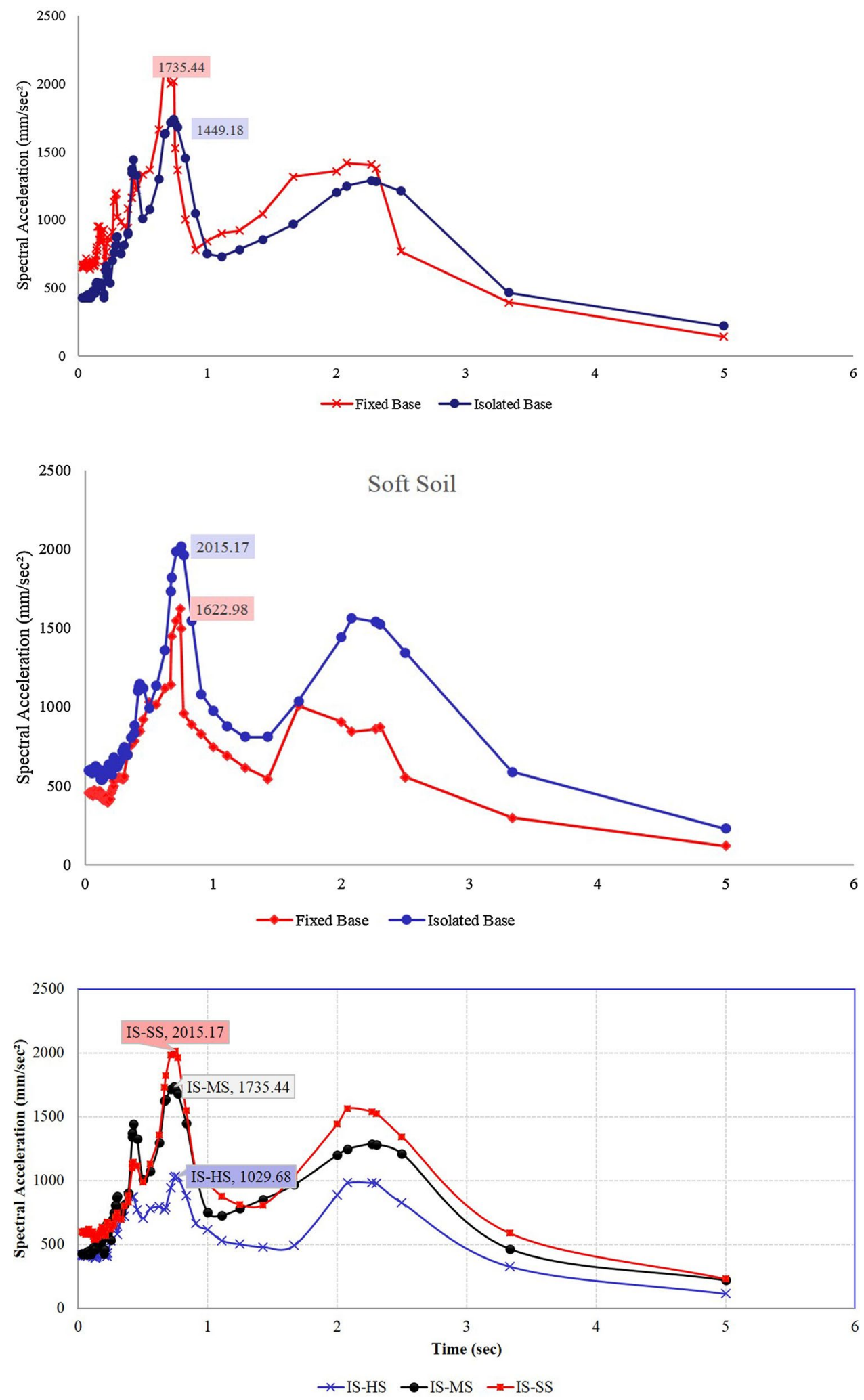

Also, as shown in Fig. 21, the spectral displacement of various soil conditions, in cases of fixed base and isolated base, is observed. The difference in spectral displacement history of hard soil condition, between fixed base and isolated base, is negligible. Whereas the spectral displacement history of medium soil, in isolated base, increases by $27.3 \%$ 
Fig. 20 Spectral displacement history of different soil types. IS isolated base, $H S$ hard soil, $M S$ medium soil, $S S$ soft soil
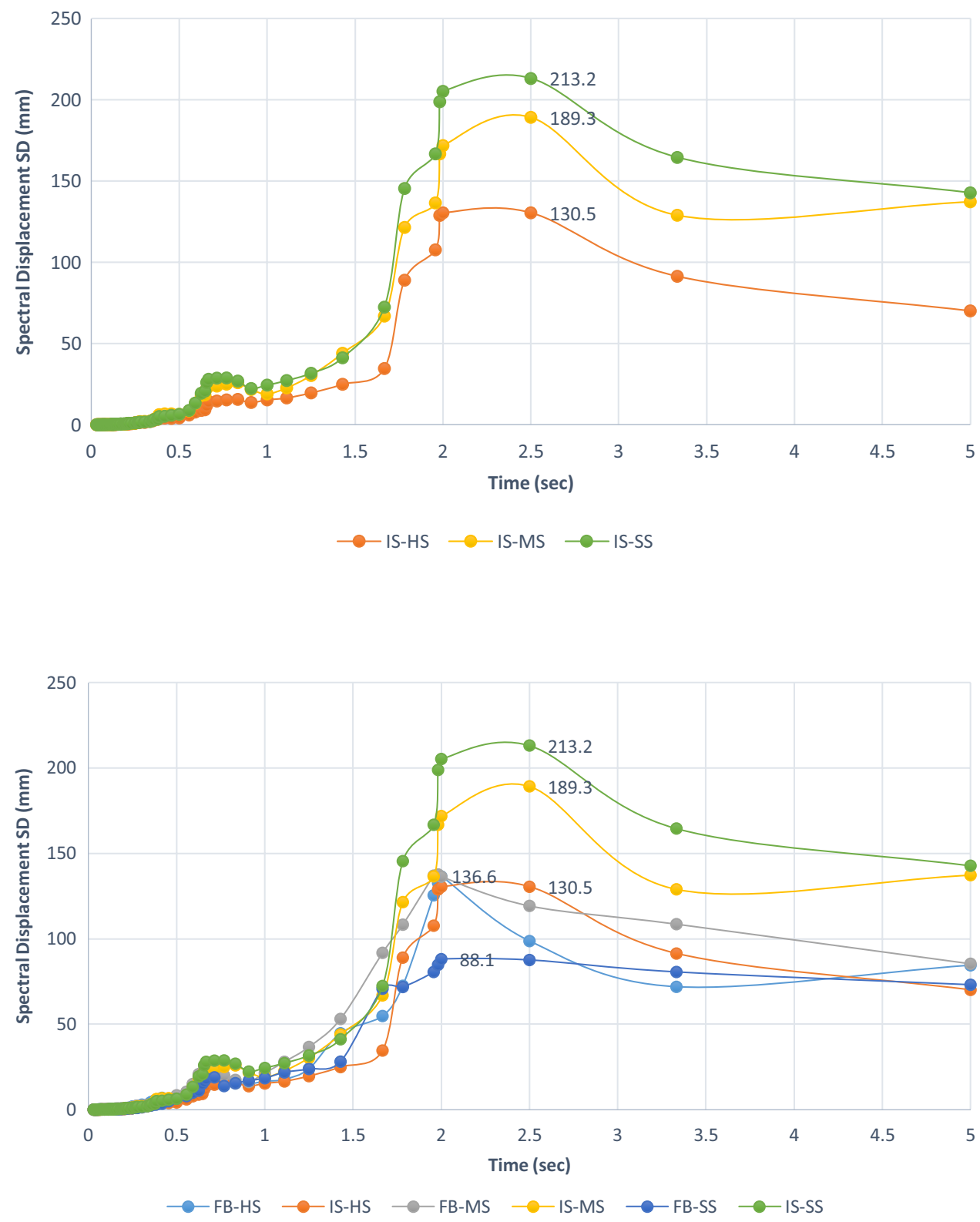

Fig. 21 Spectral displacement history of different soil types in fixed base model and isolated base model. $F B$ fixed base, $I S$ isolated base, $H S$ hard soil, $M S$ medium soil, $S S$ soft soil and $58.7 \%$ for soft soil condition, when compared with a fixed base for the same soil conditions.

\section{Conclusion}

A tall building of 12 stories with an isolated base and fixed base have been analyzed for hard, medium and soft soil conditions. The purpose of the study was to investigate the seismic performance of an isolated base building under various soil conditions according to IS code; the responses of the building, such as story displacements, story drifts, story forces, spectral acceleration at roof and spectral displacement have been studied. Time history analysis and response spectrum analysis carried out by Etabs software and El Centro earthquake matched with response spectrum as a function applied in the base of the fixed and isolated base models. After the analysis of the models it can be concluded the results as follows:

- It is observed that the value of story shear increases with decrease in stiffness of soil and so forth; it is highest for the soft soil type (SS) and lowest for hard soil type (HS).

- It is observed that the spectral acceleration history at roof level of an isolated base model increases in soft soil condition by $48.7 \%$ and $40.5 \%$ in medium soil condition when compared with hard soil.

- The paper shows that the story displacement increases with the increased flexibility of the soil; in other words, 
soft soil conditions produced the largest displacement compared with hard soil and medium soil. It is also observed that the displacement produced due to time history analysis being more than the displacement produced due to response spectrum analysis in hard soil conditions with an increase of 5\%. However, it decreases by $9.5 \%$ and $18 \%$ for medium soil condition and soft soil condition, respectively.

- The maximum story drift is produced in the first floor above the isolators for various soil conditions which attributes to the flexibility introduced by isolators. It is also observed that the story drift increases with increase in flexibility of soil. Thus, the largest drifts are created in soft soil condition.

- Hard soil and medium soil conditions are suitable for multi-story isolation structures according to the response of base isolation building.

Funding No funding information available.

Open Access This article is distributed under the terms of the Creative Commons Attribution 4.0 International License (http://creativeco mmons.org/licenses/by/4.0/), which permits unrestricted use, distribution, and reproduction in any medium, provided you give appropriate credit to the original author(s) and the source, provide a link to the Creative Commons license, and indicate if changes were made.

\section{References}

Alam AKMT, Bhuiyan MAR (2013) Effect of soil-structure interaction on seismic response of a seismically isolated highway bridge pier. J Civ Eng 41(2):179-199

Baratta A, Corbi I, Jayalekshmi BR, et al (2009) Comparative evaluation of base-isolated and fixed-base buildings using a comprehensive response index. Eng Optim 135:1141-1160. https://doi. org/10.1016/j.jsv.2007.10.008
CSI (2013) CSI analysis reference manual. Computers and Structures inc, Berkeley, p 496

Dexter AR (1988) Advances in characterization of soil structure. Soil Tillage Res 11(3-4):199-238

Gjorgjiev I (2012) Effects of soil medium on response of base isolated multistory frame structures. In: 15th World conference on earthquake engineering

Hassan A, Pal S (2017) Performance analysis of base isolation \& fixed, pp 1-5

Hatami F (2015) Effects of soil-structure interaction on the seismic response of base isolated in high-rise buildings. Int J Struct Civ Eng Res 4(3):237-242. https://doi.org/10.18178/ijsce r.4.3.237-242

Jain SK (2003) Review of Indian seismic code, IS 1893 (Part 1): 2002. Indian Concr J 77(11):1414-1422

Jayalekshmi BR, Chinmayi HK (2016) Effect of soil stiffness on seismic response of reinforced concrete buildings with shear walls. Innov Infrastruct Solut 1(1):2

Magade SB, Patankar JP (2008) Effect of soil structure interaction on the dynamic behavior of buildings. In: Second international conference on emerging trends in engineering (SICETE). IOSR Journal of mechanical and civil engineering, Pune, pp 9-14.

Mondal G, Jain SK (2005) Design of non-structural elements for buildings: a review of codal provisions. Indian Concr J 79(8):22-28

Naeim F, Lew M (1995) On the use of design spectrum compatible time histories. Earthq Spectra 11(1):111-127

O. F. I. Standards. Plain and reinforced concrete-code of practice. Concrete, no. July, 2000

Pietra D, Pampanin S, Mayes RL, Wetzel NG, Feng D (2015) Design of base-isolated buildings: an overview of international codes. Bull N Z Soc Earthq Eng 48(2):118-135

Ramallo JC et al (2008) Effect of soil stiffness on seismic response of reinforced concrete buildings with shear walls. Eng Optim 135(11):1141-1160

Seifried AE, Baker JW (2016) Spectral variability and its relationship to structural response estimated from scaled and spectrummatched ground motions. Earthq Spectra 32(4):2191-2205

Strong-Motion Virtual Data Center (VDC) (2014). Global component of the center for engineering strong motion data. https://stron gmotioncenter.org/vdc/scripts/earthquakes.plx

Publisher's Note Springer Nature remains neutral with regard to jurisdictional claims in published maps and institutional affiliations. 